The impact of inhibitory control, working memory and updating on definitional skills of learners with and without Developmental Language Disorder

\author{
Dosi, Ifigeneia $\measuredangle$ \\ Democritus University of Thrace, Greece (idosi@helit.duth.gr)
}

Received: 4 August 2021

Available Online: 17 August 2021
Revised: 8 August 2021 DOI: $10.5861 /$ ijrse.2021.a055

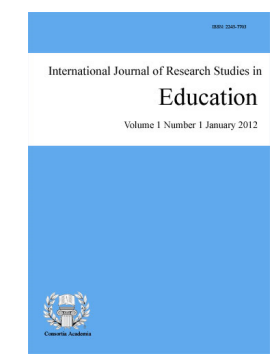

ISSN: 2243-7703 Online ISSN: 2243-7711

\title{
Abstract
}

This study investigated the effect of executive functions (EF) (inhibition, working memory and updating) on definitional skills of learners with and without Developmental Language Disorder (DLD). A good/formal definition elicits the highest number of inferences at the lowest cost. Many theories about mental lexicon organization suggest that specific words are activated and/or suppressed. Nevertheless, very limited studies have attempted to examine whether similar procedures occur in the development of definitional skills. Previous studies indicated that learners with DLD have lower EF and definitional skills, which, however, do not correlate. In contrast, a link between EF and definitional skills arise in non-impaired learners. In this study, thirty-six learners divided into three groups (a DLD and two age- and vocabulary-matched control groups; $\mathrm{CG}$ ) were tested through a definitional and three EF tasks. The two CGs produced better definitions than the DLD group. Moreover, age-matched CG scored higher than the other groups in EF tasks, while the vocabulary-matched CG outperformed the DLD only in updating. Correlations between definitions and EF emerged only in the age-matched CG. Concluding, EF and definitional skills of the DLD group seem to be deviant; while the link between EF and definitional skills may require more time to emerge in DLD learners, since it was also not found in the vocabulary-matched CG. Nevertheless, it was found in the other $\mathrm{CG}$, suggesting that forming a good definition irrelevant words should be suppressed, appropriate words and form should be recalled, and useless information should be discarded.

Keywords: inhibitory control, verbal working memory, updating, definitional skills, developmental language disorder 


\section{The impact of inhibitory control, working memory and updating on definitional skills of learners with and without Developmental Language Disorder}

\section{Introduction}

The importance of definitions has been investigated in terms of both content (i.e. semantics) and form (i.e. morphosyntax) in many different populations (typically developing learners, Gavriilidou, 2015; Snow, 1990; and learners with language disorders, Marinellie \& Johnson, 2002, 2004; Dosi \& Gavriilidou, 2020), since they depict important semantic and syntactic information.

The requirement of a 'good'/ 'formal' definition is to elicit the highest number of inferences at the lowest cost ('relevance theory', cf. Sperber \& Wilson, 1986). By 'good definition' it is meant formal definition (Snow et al., 1989). Formal definitions should include a superordinate and one characteristic of the defined object. For instance, "a guitar is a musical instrument that has six strings" (Gutierrez-Cleflen \& DeCurtis, 2009). On the other hand, informal definitions can use examples (operational definitions; e.g. courage is riding on the roller coaster), synonyms (e.g. a bush is a shrub), similar categories (e.g. a chair is similar to a sofa), or even words defined by negation (e.g. a chair is not a bench). Informal definitions include quite often tautologies (i.e., the term which is expected to be defined is repeated, e.g. "smart: I am smart"; cf. Benelli et al., 1988). Moreover, definitions also offer useful information about decontextualized language skills, lexical knowledge and morphosyntactic abilities. Learners progressively produce definitions "that are both inferentially rich and maximally informative to the hearer" (Watson, 1985, p. 222). In younger learners or in adults with low literacy levels, definitions are more informal and formal definitions gradually emerge in adolescence and they are further mastered in adulthood; of course, literacy and schooling affect the definitions produced (Dourou et al., 2020).

Definitional skills of learners with Developmental Language Disorder (DLD, previously known as Specific Language Impairment/SLI) are less studied (Gutierrez-Clellen \& DeCurtis, 1999; Marinellie \& Johnson, 2002; Mohammadi et al., 2011; Dosi \& Gavriilidou, 2020). By DLD, we refer to individuals with absence of hearing, intellectual or emotional impairments; though with language deficits (Leonard, 2014) and discrepancies in cognitive abilities (i.e. working memory, updating, inhibition; Marton et al., 2007; Dosi \& Gavriilidou, 2020). An updated definition of the disorder includes children whose non-verbal IQ "is neither impaired enough to justify a diagnosis of intellectual disability nor good enough to be discrepant with overall language level" (Bishop, 2017, p. 679). A clear answer has not been given yet about language abilities of learners with DLD. Two general approaches suggest that: (a) the cause of DLD locates within the language system, and more specifically, in the deficient representations in the grammatical system (Gopnic \& Crago, 1991; Rice et al., 1995); or (b) the disorder is due to a deficiency in the non-linguistic processing mechanism (Ullman, 2004). Moreover, the debate about delayed vs. deviant language abilities still exists (Meir \& Armon-Lotem, 2017). On the one hand, the delay hypothesis supports that typical acquisitional patterns are followed, albeit with a delay; thus, it is expected DLD learners to perform like their younger language-matched controls (Rice et al., 1995). On the other hand, the deviance hypothesis claimed atypical acquisitional patterns that are not detected in younger language-matched TD learners (Bishop, 2014; Briscoe et al., 2001). According to, Conti-Ramsden et al. (2012), language deficits in learners with DLD that persist into adolescence may suggest that the initial delay becomes ultimately a deviance.

Previous studies in learners with DLD have shown that this group produces predominately informal definitions, which also contain less information (Marinellie \& Johnson, 2002); conceivably because formal definitions require abstract thinking and better organization (Ponari et al., 2018) and go beyond the functional use of words (Gutierrez-Clellen \& DeCurtis, 2009). In this direction, other studies suggested that learners with DLD have shallower word knowledge than their TD grade-mates, and they face persistent difficulties in word organization, associations (McGregor et al., 2013) and metalinguistic abilities (Marinellie \& Johnson, 2002).

98 Consortia Academia Publishing (A partner of Network of Professional Researchers and Educators) 
Inhibitory control, working memory and definitional skills of learners with and without language disorder

This claim is further supported by Krzemien et al. (2021), who found that some aspects of lexical acquisition (i.e., word generalization) were similar to TD age-matched children when they were controlled for their vocabulary, which suggests that DLD learners' language abilities are delayed rather than deviant. Mohammadi et al. (2011) noted that the lower definitional skills of learners with DLD are due to their language difficulties, which prevent full meaning representations. Additionally, learners with DLD have deficient working memory abilities, deficits in speech perception, and in processing speed (Leonard, 2014). According to Bishop (1997) this group has more limited processing capacity than their non-impaired peers. Based on the "inefficient inhibition hypothesis" (Bjorklund \& Harnishfeger, 1990; Wilson \& Kipp, 1998) learners with DLD are less efficient in inhibition and cannot, thus, suppress and keep out irrelevant information from their memory (Gillam et al., 1995).

The role of executive functions (EF, e.g. inhibition, working memory and updating) in definitional skills is under-researched. Although, there are many theories about mental lexicon organization of non-impaired learners (Semantic Feature Model, Smith et al., 1974; Spreading Activation Model, Collins \& Loftus, 1975; Hierarchical Network Model, Collins \& Quillans, 1969), claiming that specific words are activated and others are suppressed by the speaker, very limited studies have attempted to examine whether similar procedures occur in the development of definitions. Addressing this issue, Dosi and Gavriilidou (2020) tested the role of cognitive abilities in the definitional skills of learners with and without DLD. Their results have shown correlations between working memory, vocabulary and definitions albeit only in the non-impaired group. The authors suggested that the development of definitional skills is driven by different mechanisms in (non-)impaired learners. To date, no other studies have tested the impact of EF (i.e., inhibition, working memory and updating) on the definitional skills of (non-)impaired learners.

\section{This study}

Addressing this gap, the present study aims to investigate the impact of inhibitory control, working memory and updating on definitional skills of learners with and without Developmental Language Disorder. It extends the previous research of Dosi and Gavriilidou (2020) on the role of EF, by testing the role of inhibitory control and adding a vocabulary-matched group, in order to disentangle language issues from age-related issues and to shed light on the debate about delayed vs. deviant language abilities. To this end, two research questions (RQ) and hypotheses (RH) are formed as follows:

RQ1: Are learners' with DLD EF and definitional skills delayed or deviant?

RH1: It is expected that the age-matched CG will outperform the DLD group in both EF and definitions (Dosi \& Gavriilidou, 2020), while the vocabulary-matched CG will score similarly to learners with DLD (Rice et al., 1995).

RQ2: Do EF (i.e. inhibitory control, verbal working memory and updating) affect definitional skills; and if so, do they affect the three groups in the same way?

RH2: It is expected that in order to form a 'good' definition, the irrelevant information and words should be suppressed (i.e. inhibitory control). In addition, in order to produce a 'good' definition, you should remember and recall the appropriate words and the proper form (i.e. working memory capacity) and discard any useless information (i.e. updating). We expect that at least for the typically developing learners this model will be confirmed. Based on Dosi and Gavriilidou (2020), it is expected the development of definitions to be driven by different mechanisms in the learners with DLD (Ullman, 2004).

\section{Method}

Participants - Thirty-six monolingual Greek-speaking learners aged from 5;5-12 years (Mean: 8;1; SD: 1.6) participated in this study. Participants formed three groups (the experimental group and two control groups; the 
one matched on the chronological age and the other on the vocabulary age). Two baseline tasks were given (Table 1); (a) a non-verbal intelligence task (Raven et al., 2008) and (b) an expressive vocabulary task (Vogindroukas et al., 2009), which is normed for 3-to-10-year-old Greek-speaking learners. The tasks aimed to ascertain that all participants' general non-verbal intelligence is normal (cut-off point was 85) and to detect their vocabulary knowledge abilities in order to be matched accordingly.

The experimental group (henceforth DLD group) consisted of twelve learners with DLD (age range: 7;3-11;8 years; mean age: 9;1, SD: 1.2). The DLD learners met the following selection criteria in order to be included in the experimental group: absence of auditory or visual problems; no evidence of neurological impairment; absence of disorders in social interaction and communication, such as autism (Leonard, 2014). Moreover, their non-verbal abilities were within the normal limits for their chronological age (Bishop, 2017) and their verbal abilities (vocabulary and morphosyntax) were at least 2 SD below the expected normative mean of chronologically age-matched peers (Stark \& Tallal, 1981). Their non-verbal fluid intelligence was also verified by study testing and should be at least 85 . The participants of this group were attending speech and language therapies, for at least three years.

The two control groups of TD learners were recruited from Greek primary schools. Based on their teachers' reports they had normal language skills and absence of any learning difficulties. In the first Control Group (henceforth CG1), each participant was matched on age to a learner from the DLD group. Each age-matched learner should be up to 6-months younger/older to the DLD learner. The CG1 consisted of twelve TD learners of equivalent chronological age (age range: 7;2-12 years; mean age: 8;5, SD: 1.6). The second Control Group (henceforth CG2) consisted of twelve younger TD learners of equivalent vocabulary age as the learners of the DLD group (age range: 5;5-7;5 years; mean age: 6;6, SD: 0.7; based on the categorization of Levy \& Schaeffer, 2003). The expressive vocabulary tasks used informs about the lexical age of the learner based on their scores; each vocabulary-matched learner should, thus, be up to 6-months younger/older to the equivalent DLD learner.

Non-parametric criteria (Kruskal-Wallis test or Mann Whitney test) were performed. The results revealed age differences among the groups $(H(2)=18.575, p<.001)$. Hence, the CG2 was significantly younger that the DLD group and the CG1 $(U=1.000, p<.001$ and $U=18.500, p=.001)$; while no difference was found between the DLD and CG1 groups $(U=48.500, p=.912)$.

Table 1

Participants' profile

\begin{tabular}{lcccc}
\hline Group & $\mathrm{N}$ & $\begin{array}{c}\text { Chronological age } \\
\text { (years; } S D)\end{array}$ & $\begin{array}{c}\text { Expressive vocabulary scores } \\
\text { (vocabulary age; } S D)\end{array}$ & $\begin{array}{c}\text { Non-verbal intelligence } \\
(S D)\end{array}$ \\
\hline DLD & 12 & $9 ; 1(1.2)$ & $7.2(1.7)$ & $98.5(4.5)$ \\
CG1 & 12 & $8 ; 5(1.6)$ & $10(1.6)$ & $102.6(3.4)$ \\
CG2 & 12 & $6 ; 6(0.7)$ & $6.9(0.7)$ & $87.8(2.8)$ \\
\hline
\end{tabular}

The groups differed in their expressive vocabulary skills $(H(2)=17.952, p<.001)$. Hence, CG1 outperformed both DLD and CG2 $(U=14.500, p<.001$; and $U=4.500, p<.001$, respectively), whereas no differences were found between DLD and CG2 $(U=63.000, p=.630)$. In the non-verbal intelligence, differences were observed between the groups $(H(2)=23.507, p<.001)$. More specifically, the CG2 differ from the two older groups $(U=1.000, p<.001$, for both comparisons), while the DLD and the CG1 did not differ $(U=52.000, p=.266)$. The participants were matched on gender and socio-economic background. Informed consent in writing was obtained beforehand from parents/guardians of all learners included in the study.

Material - Apart from the baseline tasks, a definitional task and three EF tasks, testing verbal EF (i.e. inhibition, working memory and updating) were administered. The word definitional task (as used by Dourou, 2019; Dosi \& Gavriilidou, 2020) investigated participants' definitional skills. It included 16 words (nouns, verbs and adjectives). Participants' responses were evaluated with respect to both content (meaning) and form 
Inhibitory control, working memory and definitional skills of learners with and without language disorder

(syntactic structure) (based on the study of Marinellie \& Johnson, 2002, 2004).

In content, if the participant pointed the defined object or used gestures in describing the word, they received 0-point. As Low-level responses were deemed Function, or a Description of the word, Concrete Examples, and Associations (1 point). As Mid-level responses were deemed Class-Nonspecific, Class-Specific (apple: food), and Synonym (2-3 points), while High-level responses included Partially formal (the use of the superordinate term and a word characteristic; apple: a fruit that is red; 4 points), and Formal (the use of the superordinate term and at least two word characteristics; apple: it is a fruit that we bite, and it has seeds; 5 points).

Similarly, in form, non-verbal descriptions/gestures receive 0 point. As Low-level responses were considered the use of a Noun Phrase (apple: food; 1 point). As Mid-level responses were deemed a Verb Phrase (apple: we eat it; 2 points) and the words "something/thing" along with a referential phrase (something that has seeds; 3 points). In High-level responses were included Partial formal definitions (the superordinate category or an infinitive or verb phrase; apple: a fruit that is red; 4 points); in addition, formal definitions contained the Partial Aristotelian + a second infinitive or a nonfinite clause or a finite adverbial clause, or a prepositional phrase (apple: it is a fruit that we bite; 5 points).

The maximum score will be 80 points in content and form, respectively (16 items $\mathrm{x}$ 5). The researcher asked the participant "what does X mean?", without showing any picture/object or without any further prompt. Participants' responses were audio-taped and transcribed afterwards. Inter-judge reliability of coding was evaluated for all responses given by 36 subjects (in total 576 definitions). Any response coded identically by two independent evaluators was considered an agreement. A double-blind marking was followed. Identically coded responses were considered an agreement. The final percentage of agreement was determined by dividing the number of responses coded identically by the total number of coded definitions. The inter-judge agreement for content was $89.1 \%$. Inter-judge reliability of form coding was evaluated in a similar way and the agreement was $90 \%$.

The EF tasks were administered in order to further analyze whether definitional skills are linked to higher cognitive skills (i.e. EF). More specifically, (1) the inhibition task was an online color-word Stroop task (Stroop, 1935). The reason for choosing a verbal version of inhibitory control was because this version measures the specific lexical inhibitory mechanism that activates on the neighboring lexical representations; while the non-verbal version focuses on measurement of the whole inhibitory mechanism (Borragan et al., 2018); (2) the verbal working memory task was an off-line backwards digit recall task will be used, which measures verbal working memory (Alloway, 2007); finally, (3) the updating task was an online 2-back digit task (Kirchner, 1958) which measured the ability to update the useful information and rejecting/dismissing the unnecessary ones.

The inhibition task consisted of four-color words in Greek: RED, BLUE, GREEN and YELLOW. Each word was presented individually in one of four ink colors (red, blue, green and yellow) in such a way to yield congruent and incongruent color-word pairings. Participants were required to identify the ink color and ignore the meaning of the word through a key press on the computer keyboard. It measured both accuracy and reaction times in milliseconds. The task included congruent and incongruent trials. It was expected that participants would make more errors and to exhibit slower reaction times on the incongruent trials. Based on accuracy and reaction times (RT) the Stroop effect was calculated for each participant. We divided the RT used to complete each condition by the number of correct responses in that condition, and then subtracted the result of the congruent condition from that of the incongruent condition. The closer the Stroop effect score is to zero the better the inhibition is.

In the verbal working memory task participants were required to recall a sequence of spoken digits in reverse order. Digit sequences were audiotaped by a native speaker of Greek with the distance between the offset of a digit and the onset of the next one to be 1 second. The participant listened to the sequence and must recall it in reverse order. The number of digits to remember increased progressively over successive blocks. Correct 
Dosi, I.

recall of 4 out of the 6 trials allowed the participant to move on to the next block; if they were not reached that score the test stopped. The maximum score was 36 points.

The updating task measured standard "executive" working memory; i.e., more complex verbal working memory (Kane et al., 2007). Participants see a sequence of digits $(2,5,7,8)$, each presented-one by one-for $500 \mathrm{~ms}$, followed by a blank $2500 \mathrm{~ms}$ inter-stimulus interval. Participants should press the "J" on the keyboard if the current digit displayed was identical to the one introduced two steps back or refrain from pressing any key if the digit presented was not identical. The total items were sixty. Twenty of them were correct hits and the other forty were false hits. Both hits were transformed into percentages. The final score resulted from subtracting the false from the correct hits.

Data analyses - In order to test comparisons between the groups non-parametric tests were performed (Kruskal-Wallis tests or Mann Whitney tests) by means of SPSS25(). In addition, bivariate correlations between definitional skills and the scores on EF tasks were conducted for each group separately.

\section{Results}

In content, all groups produced more informal definitions, as Table 2 depicts. Though, differences were found between the groups $(H(2)=18.093, p<.001)$. Mann Whitney tests have revealed that the DLD group uttered more informal definitions than the other two control groups ( $U=1.000, p<.001$, for both comparisons), while no differences were confirmed between the two control groups $(U=52.000, p=.226)$. In form, the three groups performed similarly $(H(2)=2.185, p=.335)$.

Table 2

Participants' scores on the definitional task

\begin{tabular}{lccc}
\hline Group & $\mathrm{N}$ & $\begin{array}{c}\text { Content } \\
(\%, \mathrm{SD})\end{array}$ & $\begin{array}{c}\text { Form } \\
(\%, \mathrm{SD})\end{array}$ \\
\hline DLD & 12 & $21.8(6.4)$ & $41.8(8.3)$ \\
CG1 & 12 & $43.5(14.7)$ & $46.8(10.1)$ \\
CG2 & 12 & $35.6(8.5)$ & $41.9(8.4)$ \\
\hline
\end{tabular}

In the EF tasks significant differences were attested in the updating and inhibition task and marginal significant differences in the working memory task $(H(2)=26.774, p<.001 ; H(2)=18.631, p<.001 ; H(2)=5.774$, $p=.056$; respectively), as Table 3 shows. Further analyses between the groups (Mann Whitney tests) have shown that the CG1 group scored higher than the DLD in all EF tasks (working memory: $U=28.500, p=.010$; updating: $U=.000, p<.001$; inhibition: $U=16.500, p=.001)$. The CG2 performed similarly to the DLD group in working memory and inhibition $(U=55.000, p=.347 ; U=66.500, p=.755$; respectively), but they scored higher in updating $(U=.000, p<.001)$. Regarding the two control groups, the CG1 outperformed the CG2 in updating and inhibition $(U=24.500, p=.005 ; U=.000, p<.001$; respectively), but not in working memory abilities $(U=53.000$, $p=.291)$.

Table 3

Participants' scores on EF tasks

\begin{tabular}{lcccc}
\hline Group & $\mathrm{N}$ & $\begin{array}{c}\text { Working memory } \\
(\%, \mathrm{SD})\end{array}$ & $\begin{array}{c}\text { Updating } \\
(\%, \mathrm{SD})\end{array}$ & $\begin{array}{c}\text { Inhibition } \\
(\text { Mean, SD) }\end{array}$ \\
\hline DLD & 12 & $21.8(5.8)$ & $-29.1(15.0)$ & $10.6(5.1)$ \\
CG1 & 12 & $30.6(11.3)$ & $61.2(28.2)$ & $1.8(1.5)$ \\
CG2 & 12 & $24.3(6.6)$ & $27.8(5.7)$ & $9.9(4.3)$ \\
\hline
\end{tabular}

Bivariate correlations were performed for each group separately, in order to investigate associations between the definitional skills and EF abilities. Correlations were found only in the CG1, as Table 4 depicts. More specifically, both content and form of definitions correlated with working memory, updating and inhibition 
Inhibitory control, working memory and definitional skills of learners with and without language disorder (content: $r(12)=.836, p=.001 ; r(12)=.635, p=.027 ; r(12)=.631, p=.028$; respectively; form: $r(12)=.832$, $p=.001 ; r(12)=.637, p=.026 ; r(12)=.671, p=.017$; respectively).

\section{Table 4}

Correlations between the definitional task and the EF tasks

\begin{tabular}{ccccc}
\hline Group & Definitions & Working memory & Updating & Inhibition \\
\hline DLD & content & $r(12)=-.139, p=.666$ & $r(12)=.333, p=.290$ & $r(12)=-.558, p=.060$ \\
& form & $r(12)=-.354, p=.259$ & $r(12)=.294, p=.354$ & $r(12)=-.375, p=.230$ \\
\hline CG1 & content & $r(12)=.836, p=.001$ & $r(12)=.635, p=.027$ & $r(12)=.631, p=.028$ \\
& form & $r(12)=.832, p=.001$ & $r(12)=.637, p=.026$ & $r(12)=.671, p=.017$ \\
\hline CG2 & content & $r(12)=-.301, p=.342$ & $r(12)=-.285, p=.370$ & $r(12)=-.252, p=.429$ \\
& form & $r(12)=-.480, p=.115$ & $r(12)=-.252, p=.429$ & $r(12)=-.465, p=.128$ \\
\hline
\end{tabular}

\section{Discussion}

The present study investigated the effect of inhibitory control, working memory and updating on definitional skills of learners with and without DLD. The main findings indicated that the DLD group produced more informal definitional skills in content compared to typically developing learners (age-matched and vocabulary-matched). In form, no differences were attested between the groups. In EF tasks, the age-matched CG scored higher than the other groups, apart from the working memory task, in which they scored similarly to the younger CG. In addition, the DLD group scored similarly to the vocabulary-matched CG in working memory and inhibition, but not in updating, which was a very challenging task for the group.

Two research questions addressed, (a) are learners' with DLD EF and definitional skills delayed or deviant, and (b) do EF (i.e. inhibitory control, verbal working memory and updating) affect definitional skills similarly in the three groups.

The first hypothesis was partially confirmed since not only the age-matched typically developing learners (Marinellie \& Johnson, 2002; Mohammadi et al., 2011; Dosi \& Gavriilidou, 2020) but also the vocabulary-matched typically developing learners (Bishop, 2014; Briscoe et al., 2001) produced more formal definitions compared to the learners with DLD. DLD learners' definitions were less informative (Marinellie \& Johnson, 2002); conceivably due to their shallower word knowledge and their difficulties in word organization, associations (McGregor et al., 2013), their discrepancies in abstract thinking and organization (Gutierrez-Clellen \& DeCurtis, 2009; Ponari et al., 2018). These delayed language abilities might later become deviant (Conti-Ramsden et al., 2012). It is, thus, important for speech-language pathologists and teachers to enhance the definitional abilities of this group. The absence of finding any differences in form of definitions can be possibly explained by the less complex syntactic structural choices of the majority of the participants, who used mid-level responses (i.e. verb phrases) (Marinellie \& Johnson, 2002). In addition, this finding may indicate that form is a less demanding indicator (Dosi \& Gavriilidou, 2020).

Concerning the EF abilities, it is confirmed that the DLD group had lower abilities (Bjorklund \& Harnishfeger, 1990; Bishop, 1997; Wilson \& Kipp, 1998; Marton et al., 2007; Dosi \& Gavriilidou, 2020), at least compared to their typically developing peers. The absence of finding differences between the younger (vocabulary-matched) CG in inhibition and working memory may indicate that DLD learners' abilities are delayed. However, we should note that it might be an effect in the inhibition task, since the verbal version was used and the younger typically developing learners have not automatized their reading process. Therefore, this issue remains open for further research and discussion. The lower EF abilities of the DLD is possible to affect their definitional skills (Bishop, 1997; Leonard, 2014), since they struggle to suppress irrelevant information and then update the useful one, confirming the "inefficient inhibition hypothesis" (Gillam et al., 1995).

The second hypothesis was also partially confirmed, since correlations were found only in the age-matched CG (similar to Dosi \& Gavriilidou, 2020). The lack of finding correlations in the DLD group and the 
vocabulary-matched CG suggests that the two groups perform similarly; and it further supports the delay hypothesis that typical acquisitional patterns are followed, albeit with a delay (Rice et al., 1995). This may also indicate that the link between EF and definitional skills may take more time to emerge. The outcomes of the correlations in the age-matched CG affirm that a 'good' definition requires (a) the suppression of irrelevant words and forms, (b) the recall of appropriate words and forms, and (c) the updating of the useful information and the rejection of the useless words or forms. Similarly, working memory and updating are needed when the learner is exposed to definitions through input. They should remember the proper word categories, characteristics and the form of a definition and update the correct information. These outcomes can be leveraged by speech and language pathologists and teachers in order to improve their learners' definitional skills.

\section{Conclusions, educational implications, limitations and further research}

This study has added new insights about the impact of inhibitory control, working memory and updating on the development of definitional skills in learners with and without DLD. Concluding, the major findings of the study were that definitional skills of DLD learners are deviant in content, but not in form. This dissociation between content and form may imply that their abilities are possibly delayed rather than deviant (Rice et al., 1995). In addition, it might indicate that content of definitions is more demanding than form (Dosi \& Gavriilidou, 2020). Similarly, working memory capacity and inhibitory control seem to lag behind compared to their peers (Bishop, 1997; Marton et al., 2007; Dosi \& Gavriilidou, 2020); however, they seem to be delayed and not deviant; in contrast to updating which found to be a particularly demanding task for the DLD group. Finally, EF and definitional skills seem to be linked only in the older non-impaired group, which may imply that inhibitory control, working memory, updating and definitional skills correlate but it requires time for this link to arise. The outcome of the correlation is important because it shows that in order to form a good/ formal definition inappropriate words should be inhibited, by contrast, appropriate words and forms should be recalled and not needed information should be rejected.

The outcomes of the present study have crucial clinical and educational implications. Speech-language pathologists and teachers can develop evidence-based practice interventions and they can work on the enhancement of their leaners' definitional and EF skills, at once. In addition, teachers need to promote not only their learners' definitional skills but also their EF abilities, in order to boost their delayed abilities and skills and catch up their typically developing peers. It is, thus, important that teachers will adopt teaching material and techniques that enhance the aforementioned skills of their students. Moreover, school administrators can be updated and more aware of their students' difficulties in order to adjust their methodological and educational decisions based on the new data coming from recent studies. Finally, students with DLD and their parents can become more aware about the discrepancies of this group and work in this direction.

Some of the limitations of the study are the small cohort of our participants ( $n=12$, per group), the different intervention programs that the DLD participants follow, which may cause a variation on the results (Dosi \& Gavriilidou, 2020). In addition, the large age range (6-12 years old) of the DLD and the CG1 prevented to give us more reliable data. Another limitation was that a verbal inhibition task was also administered in the CG2 that has not automatized their reading skills. Future research can administer a non-verbal inhibition task.

Finally, notwithstanding that this study is preliminary, it adds value to the existing work on EF and definitional skills, by investigating correlations between less-researched parameters in a less-examined language group. We consider our findings less in terms of firm conclusions and more as an attempt to steer the future research to this direction, in order to add extra and, thus, more robust data.

Acknowledgment - This research is co-financed by Greece and the European Union (European Social Fund- ESF) through the Operational Programme «Human Resources Development, Education and Lifelong Learning» in the context of the project "Reinforcement of Postdoctoral Researchers-2nd Cycle" (MIS-5033021), implemented by the State Scholarships Foundation (IKY). 
Inhibitory control, working memory and definitional skills of learners with and without language disorder

Conflict of interest - The authors declare that they have no conflict of interest.

Ethical approval - All procedures performed in studies involving human participants were in accordance with the ethical standards of the institutional Ethics Committee of Democritus University of Thrace (60589/2111/31-8-2018) and/or national research committee and with the 1964 Helsinki declaration and its later amendments or comparable ethical standards.

\section{References}

Alloway, T. P. (2007). The automated working memory assessment. London: Pearson Assessment.

Bishop, D. V. M. (1997). Uncommon understanding: Development and disorders of language comprehension in children. Hove: Psychology Press.

Bishop, D. V. M. (2014). Problems with tense marking in children with specific language impairment: not how but when. Philosophical Transactions of the Royal Society of London. Series B, Biological Sciences, 369(1634), 20120401. http://doi.org/10.1098/rstb.2012.0401

Bishop, D. V. M. (2017). Why is it so hard to reach agreement on terminology? The case of developmental language disorder (DLD). International Journal of Language \& Communication Disorders, 52(6), 671-680.

Bjorklund, D. F., \& Harnishfeger, K. K. (1990). The resources construct in cognitive development: Diverse sources of evidence and a theory of inefficient inhibition. Developmental Review, 10(1), 48-71. https://doi.org/10.1016/0273-2297(90)90004-N

Borragan, M., Martin, C. D., de Bruin, A., \& Duñabeitia, J. A. (2018). Exploring different types of inhibition during bilingual language production. Frontiers in Psychology, 9, Article 2256. https://doi.org/10.3389/fpsyg.2018.02256

Briscoe, J., Bishop, D. V. M., \& Norbury, C. F. (2001). Phonological processing, language, and literacy: A comparison of children with mild to moderate sensorineural hearing loss and those with specific language impairment. The Journal of Child Psychology and Psychiatry and Allied Disciplines, 42(3), 329-340.

Collins, A. M., \& Loftus, E. F. (1975). A spreading-activation theory of semantic processing. Psychological Review, 82(6), 407-428. https://doi.org/10.1037/0033-295X.82.6.407

Collins, A. M., \& Quillian, M. R. (1969). Retrieval time from semantic memory. Journal of Verbal Learning \& Verbal Behavior, 8(2), 240-247. https://doi.org/10.1016/S0022-5371(69)80069-1

Conti-Ramsden, G., St Clair, M. C., Pickles, A., \& Durkin, K. (2012). Developmental trajectories of verbal and nonverbal skills in individuals with a history of specific language impairment: From childhood to adolescence. Journal of Speech, Language, and Hearing Research, 55(6), 1716-1735. https://doi.org/10.1044/1092-4388(2012/10-0182)

Dosi, I., \& Gavriilidou, Z. (2020). The role of cognitive abilities in the development of definitions by children with and without Developmental Language Disorder. Journal of Psycholinguistic Research, 49(5), 761-777. https://doi.org/10.1007/s10936-020-09711-w

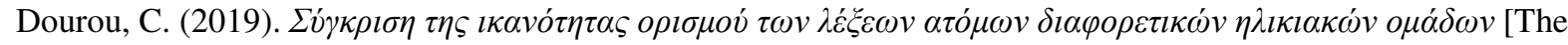
comparison of definition ability of different age groups]. Unpublished doctoral dissertation. Department of Greek Philology. Democritus University of Thrace.

Dourou, C., Gavriilidou, Z., \& Markos, A. (2020). Definitional skills and preferred definition types according to age, gender, educational level and career orientation. International Journal of Research Studies in Education, 9(2), 29-49. https://doi.org/10.5861/ijrse.2020.5021

Gavriilidou, Z. (2015). The development of noun, verb and adjective definitional awareness in Greek preschoolers, Journal of Applied Linguistics, 30, 44-58.

Gillam, R. B., Cowan, N., \& Day, L. S. (1995). Sequential memory in children with and without language impairment. Journal of Speech \& Hearing Research, 38(2),

393-402. https://doi.org/10.1044/jshr.3802.393 
Dosi, I.

Gopnik, M., \& Crago, M. B. (1991). Familial aggregation of a developmental language disorder. Cognition, 39(1), 1-50. https://doi.org/10.1016/0010-0277(91)90058-c

Gutierrez-Clellen, V., \& DeCurtis, L. (1999). Word definitional skills in Spanish speaking children with language impairment. In Communication Disorders Quarterly, 21(1), 23-31.

Kane, M. J., Conway, A., Miura, T. K., \& Colflesh, G. (2007). Working memory, attention control, and the N-back task: a question of construct validity. Journal of experimental psychology. Learning, memory, and cognition, 33(3), 615-622. https://doi.org/10.1037/0278-7393.33.3.615

Kirchner, W. K. (1958). Age differences in short-term retention of rapidly changing information. Journal of Experimental Psychology, 55(4), 352-358. https://doi.org/10.1037/h0043688

Krzemien, M., Thibaut, J. P., Jemel, B., Levaux, E., \& Maillart, C. (2021). How do children with developmental language disorder extend novel nouns?. Journal of experimental child psychology, 202, 105010. https://doi.org/10.1016/j.jecp.2020.105010

Leonard, L. B. (2014). Children with specific language impairment. Cambridge, MA: MIT Press.

Levy, Y., \& Schaeffer, J. C. (Eds.). (2003). Language competence across populations: Toward a definition of specific language impairment. Psychology Press.

McGregor, K. K., Oleson, J., Bahnsen, A., \& Duff, D. (2013). Children with developmental language impairment have vocabulary deficits characterized by limited breadth and depth. International journal of language \& communication disorders, 48(3), 307-319. https://doi.org/10.1111/1460-6984.12008

Marinellie, S. A., \& Johnson, C. J. (2002). Definitional skill in school-age children with specific language impairment. Journal of communication disorders, 35(3), 241-259. https://doi.org/10.1016/s0021-9924(02)00056-4

Marinellie, S. A., \& Johnson, C. J. (2004). Nouns and verbs: a comparison of definitional style. Journal of psycholinguistic research, 33(3), 217-235. https://doi.org/10.1023/b:jopr.0000027963.80639.88

Marton, K., Kelmenson, L., \& Pinkhasova, M. (2007). Inhibition control and working memory capacity in children with SLI. Psikhologyah: ketav 'et mada'i Yisre'eli le-'iyun ule-mehkar, 50(2), 110-121. https://doi.org/10.2117/psysoc.2007.110

Meir, N., \& Armon-Lotem, S. (2017). Delay or deviance: Old question-New evidence from bilingual children with specific language impairment (SLI). In M. LaMendola, \& J. Scott (Eds.), Proceedings of the 41st annual Boston University Conference on Language Development (pp. 495-508). Somerville, MA: Cascadilla Press.

Mohammadi, M., Nilipour, R., Shirazi, T. S., \& Rahgozar, M. (2011). Semantic Differences of Definitional skills between Persian Speaking Children with Specific Language Impairment and Normal Language Developing Children. Journal of Rehabilitation, 12(2), 48-55. http://rehabilitationj.uswr.ac.ir/article-1-886-en.html

Ponari, M., Norbury, C. F., Rotaru, A., Lenci, A., \& Vigliocco, G. (2018). Learning abstract words and concepts: insights from developmental language disorder. Philosophical transactions of the Royal Society of London. Series B, Biological sciences, 373(1752), 20170140. https://doi.org/10.1098/rstb.2017.0140

Raven, J., Court, J., \& Raven, J. C. (2008). Raven's coloured progressive matrices and vocabulary scales. London: Pearson Education.

Rice, M. L., Wexler, K., \& Cleave, P. L. (1995). Specific language impairment as a period of extended optional infinitive. Journal of Speech \& Hearing Research, 38(4), 850-863. https://doi.org/10.1044/jshr.3804.850

Smith, E. E., Shoben, E. J., \& Rips, L. J. (1974). Structure and process in semantic memory: A featural model for semantic decisions. Psychological Review, 81(3), 214-241. https://doi.org/10.1037/h0036351

Snow, C. E., Cancino, H., Gonzalez, P., \& Shriberg, E. (1989). Giving formal definitions: An oral language correlate of school literacy. In D. Bloome (Ed.), Literacy in Classrooms (pp. 233-249). Norwood, NJ: Ablex.

Snow, C. E. (1990). The development of definitional skill. Journal of Child Language, 17(3), 697-710. https://doi.org/10.1017/S0305000900010953

Sperber, D., \& Wilson, D. (1986). Relevance: Communication and cognition, Harvard University Press, 
Cambridge-Mass.

Stark, R. E., \& Tallal, P. (1981). Selection of children with specific language deficits. Journal of Speech \& Hearing Disorders, 46(2), 114-122. https://doi.org/10.1044/jshd.4602.114

Stroop, J. R. (1935). Studies of interference in serial verbal reactions. Journal of Experimental Psychology, 18(6), 643-662. https://doi.org/10.1037/h0054651

Ullman, M. T. (2004). Contributions of memory circuits to language: the declarative/procedural model. Cognition, 92(1-2), 231-270. https://doi.org/10.1016/j.cognition.2003.10.008

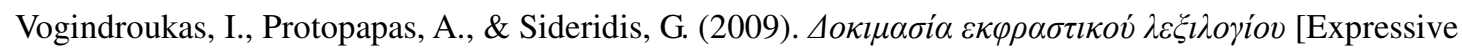
vocabulary assessment] (Greek version of Renfrew word finding vocabulary test). Chania, Crete: Glafki.

Watson, R. (1985). Towards a theory of definition. Journal of Child Language, 12(1), 181-197. https://doi.org/10.1017/S0305000900006309

Wilson, S. P., \& Kipp, K. (1998). The development of efficient inhibition: Evidence from directed-forgetting tasks. Developmental Review, 18(1), 86-123. https://doi.org/10.1006/drev.1997.0445 
Dosi, I.

108 Consortia Academia Publishing (A partner of Network of Professional Researchers and Educators) 